\title{
Kinetic Study on Free Radical Polymerization of 2-Acetamidoacrylic Acid and Formation of $\mathrm{Hydrogel}$
}

\author{
Hitoshi Tanaka, ${ }^{\dagger}$ Takeshi SuzuKa, Kazuya HADA, and Yoshihiko TeZuKA \\ Department of Optical Science and Technology, Faculty of Engineering, \\ Tokushima University, 2-1 Minamijosanjima, Tokushima 770-8506, Japan
}

(Received September 10, 1999)

\begin{abstract}
Radical polymerization of captodative (cd) substituted 2-acetamidoacrylic acid (1) was studied kinetically at $40^{\circ} \mathrm{C}$. The rate constants of propagation $\left(k_{\mathrm{p}}\right)$ and termination $\left(k_{\mathrm{t}}\right)$ of 1 were estimated by atating sector and an inhibitor method using 1,3,5-triphenylverdazyl. Termination was depressed and $k_{\mathrm{p}} / k_{\mathrm{t}}$ became high, which was responsible for the high radical polymerization reactivity of 1 in spite of the cd olefin. The hydrogel consisting of poly(acetyl dehydroalanine) network was synthesized by the copolymerization of 1 and bifunctional cross-linker with the structure analogous to 1 . The swelling ratio of the gel was dependent on the cross-linker concentration and reached a maximum of 1334 at $2 \%$ cross-linker concentration in the feed. The gel showed stimuli-responce to $\mathrm{pH}$ and electric field, i.e., the gel volume increased to twice as much when transferred from an acidic solution into an alkaline solution and the gel bent toward an anode side within a few minutes when the electric field was applied. Biodegradability of the polymers was examined using $\alpha$-chymotrypsin.
\end{abstract}

KEY WORDS Radical Polymerization / Kinetic Study / Dehydroalanine / Captodative Substitution / Hydrogel/

Captodative (cd) olefins are olefins geminally substituted with an electron-withdrawing group (captive) and electron-donating group (dative), and often display special reactivity in free radical polymerizations due to the cd stabilization and polarization effects. ${ }^{1}$ Dehydroalanines also belong to cd olefins, and the radical polymerizability of the dehydroalanines has been studied. $N$ acyl dehydroalanine would homopolymerize very easily by radical initiators to give a high molecular weight or a monolayer polymer, ${ }^{2,3}$ but unsubstituted dehydroalanine and its methyl ester as well as the $N$-methyl derivatives of the butanamide analogue would not homopolymerize. ${ }^{4,5}$ That is, the polymerizability of dehydroalanine derivatives greatly depends on substituents. Correlation between the radical polymerizability and structure of the dehydroalanines, however, has little been studied up to now, and only a preliminary kinetic study is reported for $N$-acetyl dehydroalanine, i.e., 2 -acetamidoacrylic acid (1). ${ }^{6}$

Dehydroalanine polymers have two functional groups in the side chain, and act as polyelectrolytes and so on. ${ }^{7}$ Modification of these polar side groups is easy and optical active polynucleotide ${ }^{8}$ and comb-like polymer ${ }^{9}$ have been prepared. In particular, dehydroalanine polymers have potentially hydrophilic groups, and may be expected to form the hydrogel which shows a high swelling ratio and good mechanical properties due to a long polymer chain with low concentration of cross-linking. This<smiles>C=C(NC(C)=O)C(=O)O</smiles>

1

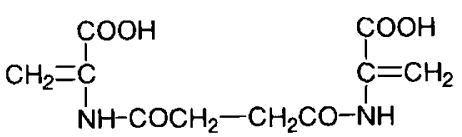

2

Schem 1.

\footnotetext{
†o whom correspondence should be addressed.
}

paper studies kinetically the radical polymerization of $\mathbf{1}$, and the formation of the stimulus-response hydrogel by the cross-linking copolymerization of 1 and the bifunctional analogue (2).

\section{EXPERIMENTAL}

\section{Materials}

1 was synthesized by reaction of pyruvic acid and acetamide in benzene solution according to the literature. $^{2}$ Purification of $\mathbf{1}$ by recrystalization from ethanol gave white needles in a $50.4 \%$ yield; $\mathrm{mp} 198-199^{\circ} \mathrm{C}$ (lit. $\left.{ }^{2} 198-199^{\circ} \mathrm{C}\right) .2$ was prepared by refluxing pyruvic acid $44.0 \mathrm{~g}(0.5 \mathrm{~mol})$ and succinamide $11.6 \mathrm{~g}(0.1 \mathrm{~mol})$ in $500 \mathrm{~mL}$ benzene for $7 \mathrm{~h}$. White powder 2 produced was removed by filtration from the supernatant benzene and washed by hot water to remove unreacted starting materials to give $2.74 \mathrm{~g}$ of pure 2 in $11.4 \%$ yield; $\mathrm{mp} 229^{\circ} \mathrm{C}$ (decomp.).

${ }^{1} \mathrm{H}$ NMR $\left(\mathrm{D}_{2} \mathrm{O}\right)$ of $2: \delta 2.53\left(\mathrm{~s}, \mathrm{CH}_{2}, 4 \mathrm{H}\right), 5.68(\mathrm{~s},=\mathrm{CH}$, $1 \mathrm{H})$, and $5.92 \mathrm{ppm}(\mathrm{s},=\mathrm{CH}, 1 \mathrm{H})$. Anal. Calcd for $\mathrm{C}_{10} \mathrm{H}_{12} \mathrm{~N}_{2} \mathrm{O}_{6}$ : C, $46.88 ; \mathrm{H}, 4.69 ; \mathrm{N}, 10.94 \%$. Found : C, $46.59 ; \mathrm{H}, 4.94 ; \mathrm{N}, 11.13 \%$.

Methyl 2-acetoxyacrylate (MAA) was synthesized by reaction of methyl pyruvate and acetic anhydride using $p$-toluenesufonic acid as catalyst in a manner similar for ethyl 2-acetoxyacrylate. ${ }^{10}$ 2,2'-Azobisisobutylonitrile (AIBN) and 1,1'-azobis (cyclohexane-1-carbonitrile) (ACHN) commercially available from Wako Chemicals and 1,3,5-triphenylverdazyl (TPV) prepared by the method of Kuhn et al. ${ }^{11}$ were all used after recrystallizations from ethanol. Commercial grade dimethyl sulfoxide (DMSO) used as solvent was purified by fractional distilation under reduced pressure.

\section{Polymerizations}

Polymerizations were carried out in a sealed ampoule with shaking at a given temperature. The ampoule con- 
taining the required amounts of reagents was degassed several times by a freeze-thaw method and then sealed under reduced pressure and placed in a constant temperature bath. The resulting polymer was isolated by pouring the contents of the ampoule into excess acetone. Kinetic study of the polymerization was carried out in DMSO in a quartz UV cell filled with $\mathrm{N}_{2}$ gas containing required amounts of reagents at $40^{\circ} \mathrm{C}$ with monitoring the polymerization by UV spectrophotoscopy. The average life-time of propagating radicals $(\tau)$ was measured in a UV-quartz cell ( $1 \mathrm{~mm}$ thickness) by the rotating sector method using a sector with the ratio of dark to light periods $=2,30 \mathrm{~W}$ chemical lamp as the light source, and $\mathrm{ACHN}$ as photosensitizer, in which the overall rate of polymerization was simultaneously estimated by following monomer concentration decay while monitoring UVabsorption at $289 \mathrm{~nm}$ due to the monomeric $\mathrm{C}=\mathrm{C}$ bond of 1 . In the determination of initiation rate $\left(R_{\mathrm{i}}\right)$, the polymerization was carried out in a UV-quartz cell $(10 \mathrm{~mm}$ thickness) using AIBN as initiator and TPV as radical trapping reagent, and $R_{\mathrm{i}}$ was estimated by following TPV concentration decay by UV spectrophotoscopy.

The copolymerization of $\mathbf{1}\left([\mathbf{1}]=1.0 \mathrm{~mol} \mathrm{~L}^{-1}\right)$ and 2 was carried out in DMSO using ammonium persulfate (5 $\mathrm{mmol} \mathrm{L}^{-1}$ ) as initiator at various molar ratios of $\mathbf{1}$ and 2 at $27^{\circ} \mathrm{C}$ for $30 \mathrm{~h}$ according to the method similar for the polymerization of 1 . The resulting copolymers, i.e., organogels, were placed into a large amount of water, and washed with distilled water several times over 7 days to form the hydrogel samples. Some gel samples were again immersed in distilled water for $24 \mathrm{~h}$ at $50^{\circ} \mathrm{C}$, and dried at $50^{\circ} \mathrm{C}$ for $6 \mathrm{~h}$ under vacuum and ground to a powder for the swelling experiments. The gel samples in the experiments of swelling ratio-variation with time and stimulus-response to $\mathrm{pH}$ and electric field were obtained by copolymerization at $[2] /[1]=0.017$ molar ratio. In copolymerization at lower $[2] /[1]$ ratios, the copolymer produced was isolated by pouring the reaction mixture into excess acetone because they were soluble in water.

\section{Hydrolyses and Biodegradation}

Poly(2-aminoacrylic acid), i.e., poly(dehydroalanine), was prepared by hydrolysis of the polymer of 1 in refluxing $70 \% \mathrm{H}_{2} \mathrm{SO}_{4}$ aqueous solution for $4 \mathrm{~h}$, followed by dialysis using seamless cellulose tube over $24 \mathrm{~h}$. In the biodegradation of the polymer of $\mathbf{1}$, the polymer sample (150 mg) was immersed in $50 \mathrm{~mL}$ buffer solution (58 mmol L ${ }^{-1}$ of $\mathrm{Na}_{2} \mathrm{HPO}_{4}$ and $9 \mathrm{mmol} \mathrm{L}^{-1} \mathrm{KH}_{2} \mathrm{PO}_{4}$, pH 7.6), followed by the addition of $\alpha$-chymotrypsin and stirred at $30^{\circ} \mathrm{C}$. The degradation of the polymer was estimated by pouring the reaction mixture into excess acetone and weighing the precipitated polymer.

\section{Measurements}

The swelling ratio $\left(W / W_{0}\right)$ was defined as the weight of absorbed water $(W)$ per weight of dried gel $\left(W_{0}\right)$ at $27^{\circ} \mathrm{C}$. Equilibrium swelling weights for the gel in water were measured using a bag made of nylon ( $58 \mu \mathrm{m}, 260$ mesh). Electric field response was examined by observing the gel shape when the electric field of $30 \mathrm{~V}$ was applied to the gel sample $\left(5 \times 70 \mathrm{~mm}^{2}\right)$ placed between the electrodes kept at $10 \mathrm{~cm}$ in aqueous solution. To study gel swelling at different $\mathrm{pH}$-values, the weighed dry gel sample was put in buffer solution of $\mathrm{CH}_{3} \mathrm{COOH} /$ $\mathrm{CH}_{3} \mathrm{COONa}$ or $\mathrm{NH}_{4} \mathrm{Cl} / \mathrm{NH}_{3}$, and ramained in solution at $27^{\circ} \mathrm{C}$ for $2 \mathrm{~h}$. The gel sample was weighed and $\mathrm{pH}$ of the exterior solution was measured.

${ }^{1} \mathrm{H}$ NMR spectrum was measured on a JEOL JNM-MY 60 spectrometer at $60 \mathrm{MHz}$ in deuterated-DMF (DMF$d_{7}$ ) using tetramethylsilane as internal standard or in $\mathrm{D}_{2} \mathrm{O} / \mathrm{NaOD}$. UV absorption was recorded on Shimadzu UV-1600PC spectrophotometer in DMSO.

\section{RESULTS AND DISCUSSION}

\section{Polymerization of $\mathbf{1}$}

Radical polymerization of 1 gives a high molecular weight polymer ${ }^{2}$ and proceeds through the conventional radical polymerization kinetics, ${ }^{6}$ i.e., the overall polymerization rate $\left(R_{\mathrm{p}}\right)$ depends on the square root of the initiator concentration and first order of the monomer concentration in DMSO. The polymerization kinetics using sector and inhibitor were thus studied on the basis of the rate equation familiar in ordinal radical polymerization. Figure 1 depicts the results obtained by the rotating sector experiment in the polymerization of 1 in DMSO using $\mathrm{ACHN}$ as initiator at $40^{\circ} \mathrm{C}$, in which $R_{\mathrm{ps}}$ and $R_{\mathrm{pL}}$ represent the polymerization rates in intermittent irradiation of light using a sector and stationary irradiation of light, respectively. In this experiment, $R_{\mathrm{pd}} / R_{\mathrm{pL}}$ was 0.09 , where $R_{\mathrm{pd}}$ is the polymerization rate in the dark. From this Figure, average life-time of propagating radicals $(\tau)$ was estimated to be $2.15 \mathrm{~s}$. TPV has been reported to be useful and convenient inhibitor for determining the initiation rate $\left(R_{\mathrm{i}}\right)$ because it absorbs light in the region $(720 \mathrm{~nm})$ where other reagents such as monomer and initiator have no absorption of light and hence, it is easy to estimate the induction period $(t)$ by UV spectrophotoscopy according to the equation : $R_{\mathrm{i}}=[\mathrm{TPV}] / t .^{12}$ In the concentration of $[\mathrm{TPV}]=1.00 \times 10^{-5} \mathrm{~mol} \mathrm{~L}-1$ and [AIBN] $=2.00 \times 10^{-2} \mathrm{~mol} \mathrm{~L}^{-1}$, the induction period $(t)$ was estimated to be $200 \mathrm{~min}$, so that $R_{\mathrm{i}}=8.33 \times 10^{-9} \mathrm{~mol} \mathrm{~L}^{-1} \mathrm{~s}$.

Table I summarizes individual rate constants of the polymerization of $\mathbf{1}$, in which the rate constants of the propagation $\left(k_{\mathrm{p}}\right)$ and termination $\left(k_{\mathrm{t}}\right)$ were calculated according to the following equations. In this Table, the rate

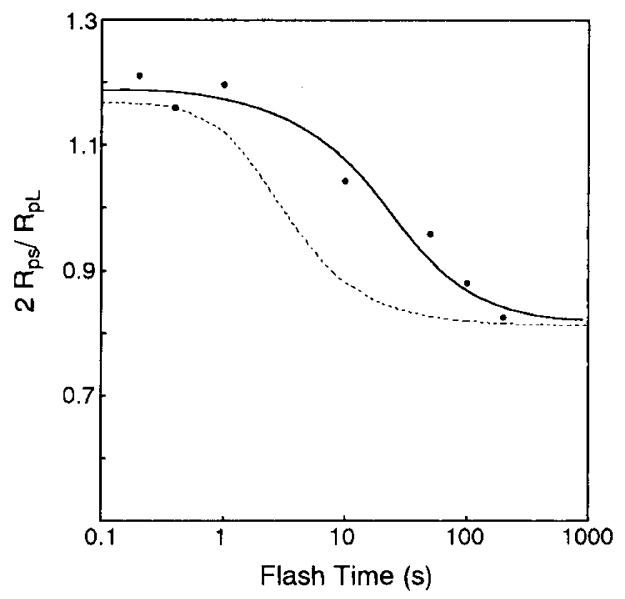

Figure 1. Determination of average life time of propagating radicals generated from 1. --. : Calculated for $R_{\mathrm{pd}} / R_{\mathrm{pL}}=0.09$ and $\tau=$ $1.00 \mathrm{~s}$, and see the text for the abbreviations of $R_{\mathrm{ps}}, R_{\mathrm{pL}}$, and $R_{\mathrm{pd}}$. 
Table I. Rate constants of radical polymerizations of various olefins at $40^{\circ} \mathrm{C}$

\begin{tabular}{lccccc}
\hline Monomer & $\left(k_{\mathrm{p}} / k_{\mathrm{t}}\right) \cdot 10^{6}$ & $\frac{\left(k_{\mathrm{p}}^{2} / k_{\mathrm{t}}\right) \cdot 10^{3}}{\mathrm{~L} \mathrm{~mol}^{-1} \mathrm{~s}^{-1}}$ & $\frac{k_{\mathrm{p}} \cdot 10^{-2}}{\mathrm{~L} \mathrm{~mol}^{-1} \mathrm{~s}^{-1}}$ & & $\frac{k_{\mathrm{t}} \cdot 10^{-6}}{\mathrm{~L} \mathrm{~mol}^{-1} \mathrm{~s}^{-1}}$ \\
\hline 1 & 144 & 189 & 13.1 & 9.10 \\
MAA $^{\mathrm{a}}$ & $(16.5)$ & 2.96 & 1.80 & 10.9 \\
MMA $^{\mathrm{b}}$ & 8.92 & - & - & - \\
MMA $^{\mathrm{b}}$ & 13.6 & - & 5.96 & 43.8 \\
Styrene $^{\mathrm{b}}$ & 2.77 & - & $(1.02)$ & $(36.8)$ \\
\hline
\end{tabular}

${ }^{a}$ See ref 13 except $k_{\mathrm{t}}$ obtained in this study. The value in parenthesis was calculated from $k_{\mathrm{t}}$ and $k_{\mathrm{p}}$. MAA: methy 2acetoxyacrylate. ${ }^{\mathrm{b}}$ See ref 14 . The values in parentheses for styrene are cited from data of other authors in ref 14 .

constants of the elementary reactions of some vinyl

$$
\begin{aligned}
& k_{\mathrm{p}} / k_{\mathrm{t}}=R_{\mathrm{p}} \tau /[\mathbf{1}] \\
& k_{\mathrm{p}}{ }^{2} / k_{\mathrm{t}}=R_{\mathrm{p}}{ }^{2} / R_{\mathrm{i}}[\mathbf{1}]^{2}
\end{aligned}
$$

monomers including cd substituted MAA, ${ }^{13}$ methyl methacrylate (MMA), and styrene are also listed for comparison, ${ }^{14}$ in which $k_{\mathrm{t}}$ of MAA was estimated from $k_{\mathrm{p}}$ already determined by $\mathrm{ESR}^{13}$ and $k_{\mathrm{p}}{ }^{2} / k_{\mathrm{t}}\left(2.96 \times 10^{-3}\right.$ $\mathrm{L} \mathrm{mol}^{-1} \mathrm{~s}$ ) calculated from the initiation rate in this study using TPV in 1,1,2-trichloroethane in a similar manner for 1 . Obviously, $k_{\mathrm{p}}$ of $\mathbf{1}$ is higher, whereas $k_{\mathrm{t}}$ is lower than those of other monomers listed, and hence $k_{\mathrm{p}} /$ $k_{\mathrm{t}}$ becomes high. This is responsible for the high radical polymerization reactivity of $\mathbf{1}$ in spite of the cd olefin. Characteristic behavior, i.e., electric interaction between the polymer chains $\mathrm{s}^{2,3}$ and significant variation of $R_{\mathrm{p}}$ with the solvents used, ${ }^{6}$ has been pointed out for the polymer and polymerization of 1 . The restriction of mobility of radical chains as well as stablilization of the propagating radical ends should thus be taken into account to some extent in the polymerization of 1 owing to the association between monomers and polymers and captodative stabilization effect, ${ }^{15}$ and it may reflect the relatively large $k_{\mathrm{p}} / k_{\mathrm{t}}$ of $\mathbf{1}$ as seen in the polymerization of MAA. $^{13}$

Enzymatic degradation of the polymer of 1 was examined using $\alpha$-chymotrypsin since polyamide has been reported to be degradable in the presence of $\alpha$ chymotrypsin. ${ }^{16}$ About $30 \%$ weight loss of the polymer was observed after immersing in the buffer solution containing the enzyme for 2 days at $30^{\circ} \mathrm{C}$. Detailed study on the biodegradation is now in progress.

\section{Formation and Characteristics of Hydrogel}

It is of interest that the homopolymer of 1 is readily soluble in water in contrast to the monomer 1 and hydrolyzed homopolymer of $1 .^{17}$ To prepare a hydrogel, $\mathbf{1}$ and 2 were copolymerized at $27^{\circ} \mathrm{C}$ for $30 \mathrm{~h}$ at molar ratios of $[2] /[1]=0.10,0.050,0.033,0.020,0.017,0.013$, and 0.010 . The polymerizations proceeded smoothly to give a polymer in high yield, i.e., $85.7-100 \%$ in such conditions. Large portions of the copolymers obtained at molar ratios of $[2] /[1]=0.013$ and 0.010 were soluble in water and DMSO probably because of the formation of an insufficient network, but all other copolymers were insoluble in organic solvents and water and swelled in water due to crosslinking as shown in Scheme 2. To examine the network structure, the copolymerization reactivity of 1 and 2 was followed by monitoring decrease in UV absorption

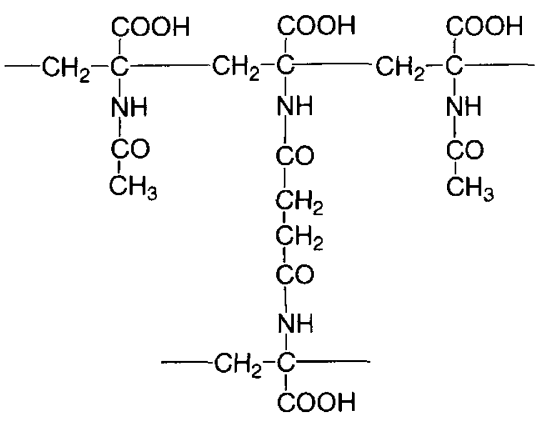

Schem 2.

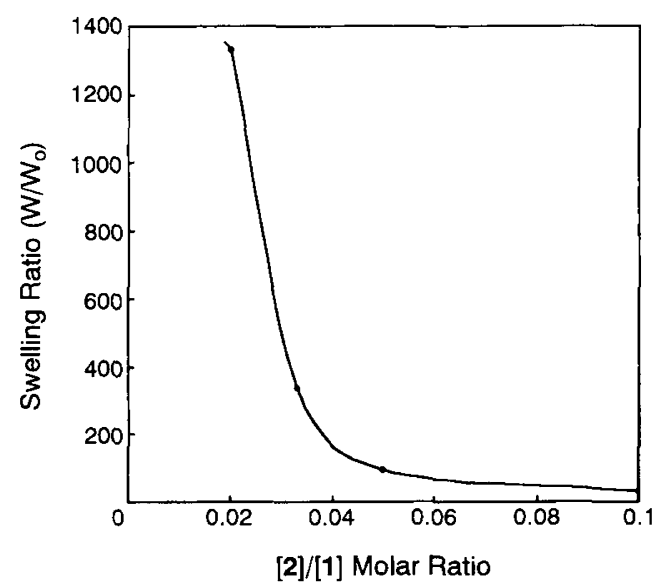

Figure 2. Dependence of cross-linker concentration in the copolymerization feed on the swelling ratio of the gel.

of the monomers at $295 \mathrm{~nm}$ during the copolymerization at several [2]/[1] ratios since both $\mathbf{1}$ and $\mathbf{2}$ show a small absorption at $295 \mathrm{~nm}$ due to the conjugated $\mathrm{C}=\mathrm{C}$ double bonds of the monomers. Absorbance at $295 \mathrm{~nm}$ decreased gradually at nearly the same rate independent of [2]/[1] ratios at the initial stage of the copolymerization, suggesting similar reactivity of 1 with 2 in the copolymerization as expected from their structures. The resulting gels may thus be considered composed of networks of homogeneously cross-linked polymers although some irregular units may be incorporated into the copolymer at latter stages of copolymerization due to gel effects and so on.

Figure 2 shows the dependence of cross-linker concentrations in the copolymerization feed $\left([\mathbf{1}]=1.0 \mathrm{~mol} \mathrm{~L}^{-1}\right)$ on the swelling ratio of the copolymer. Apparently, the swelling ratio increases with decreasing cross-linker concentration as is generally known, ${ }^{18}$ and finally reaches maximum of 1334 at $[2] /[1]=0.02$ molar ratio. The swelling ratio of 1334 obtained is comparable to that of acrylic gels used as water-absorbing materials. ${ }^{19}$ In $0.9 \% \mathrm{NaCl}$ aqueous solution, the swelling ratio was reduced to $c a .100$ for such hydrogel. Figure 3 shows the time-variation of the swelling ratio of the gel prepared by the copolymerization at $[\mathbf{2}] /[\mathbf{1}]=0.017$ molar ratio. The gel absorbs almost half the potentially absorbing water within a few minutes and gradually reaches saturation. The swelling ratio varies little with temperature in the range from 20 to $70^{\circ} \mathrm{C}$, but is dependent on $\mathrm{pH}$ of the medium and the swelling ratio increases with $\mathrm{pH}$ of 


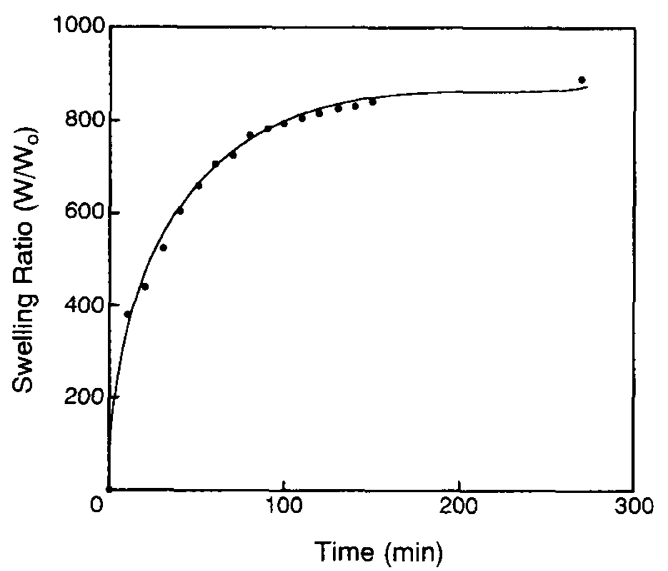

Figure 3. Swelling ratio of the gel as a function of immersion time in distilled water.

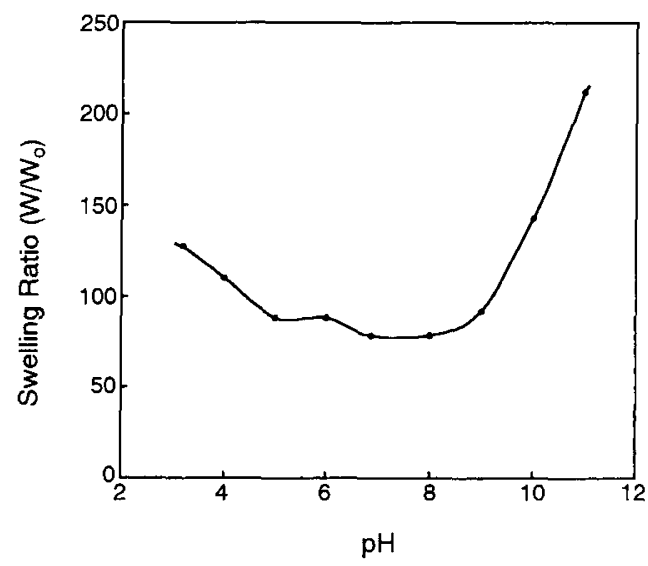

Figure 4. Dependence of the swelling ratio of the gel on the $\mathrm{pH}$ of aqueous solution surrounding the gel sample.

the environment at $\mathrm{pH} 3$ to $\mathrm{pH} 11$ as seen in Figure 4. At $\mathrm{pH}=11$, the volume of the gel was about twice that in acidic solution. This may be attributed to the electrostatic repulsion between carboxylate anions in the side chains generated by dissociattion of the carboxylic acid in alkaline solution.

Figure 5 indicates the gel shape before and after applying an electric field, in which the left-hand side is the anode and the right-hand side is the cathode. As clearly seen in this picture, the gel bends with the anode side under an electric field. Responce time is greatly dependent on the conditions, and it takes only a few minutes in $1.0 \mathrm{wt} \% \mathrm{NaCl}$ aqueous solution, but about $4 \mathrm{~h}$ in distilled water. This may be explained by gel ionization. ${ }^{20}$ The gel swelling upon ionization gradually occurs in distilled water mainly bacause of the slow increase of the osmotic pressure exerted by mobil counterions. In $\mathrm{NaCl}$ aqueous solution, however, the anode side is smoothly acidified with chloride ions, whereas the cathode side is alkalized with sodium ions. This brings about rapid change in anion and cation distribution around the gel, followed by increase in osmotic pressure of the external solution and electrostatical screening of the gel charges leading to the gel shrinkage in the anode side and the swelling in the cathode side. Shrinking and swelling on each side force the gel to bend as seen in Figure 5 .
(A)

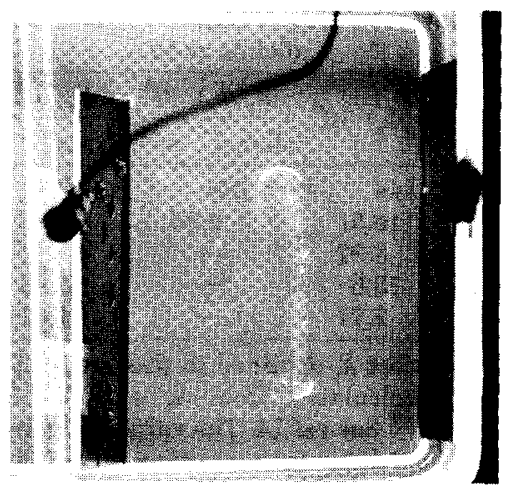

(B)

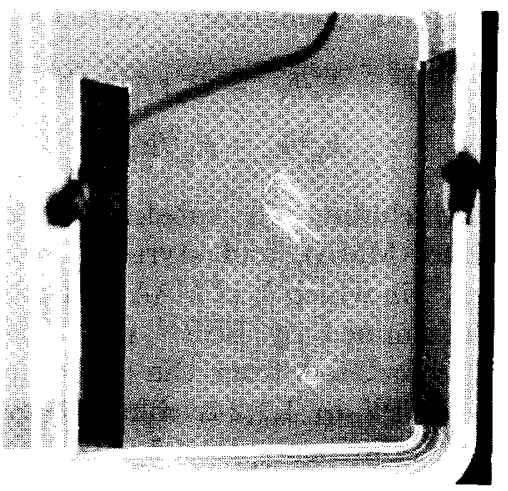

Figure 5. Variation in gel shape with application of an electric field of $30 \mathrm{~V}$. Before (A) and after (B) application of the electric field.

\section{REFERENCES AND NOTES}

1. H. Tanaka, Trends Polym. Sci., 1, 361(1993); 4, 106(1996).

2. R. S. Asquith, K. L. Gardner, and K. W. Yeung, J. Polym. Sci. ; Polym. Chem. Ed., 16, 3275(1978).

3. R. E. Hermes, L. J. Mathias, and J. W. Virden, Jr., Macromolecules, 20, 901(1987).

4. N. Schmidt, J. Hausler, E. Ohler, and H. Poisel, Prog. Chem. Org. Nat. Prod., 37, 251(1979).

5. R. E. Hermes and L. J. Mathias, J. Polym. Bull., 17, 189 (1987).

6. S. Masuda, K. Minagawa, T. Kobayashi, and M. Tanaka, Eur. Polym. J., 34, 1081(1998).

7. S. Sakakibara, Bull. Chem. Soc. Jpn., 34, 174(1961).

8. K. A. Brankt and C. G. Oberberger, Nouv. J. Chim., 6, 673 (1982).

9. N. A. Plate and V. P. Shibayev, Macromol. Rev., 8, 117(1974).

10. J. Wolinsky, R. Novac, and R. Vasileff, J. Org. Chem., 29, 3596(1964).

11. R. Kuhn and N. Trischmann, Monatsh, 95, 457(1964).

12. M. Kinoshita and Y. Miura, Makromol, Chem., 124, 211 (1965).

13. H. Tanaka and S. Yoshida, Macromolecules, 28, 8117(1995).

14. J. Brandrup and E. H. Immergut, "Polymer Handbook", 3rd ed, John Wiley \& Sons, New York, N.Y., 1989.

15. H. G. Viehe, Z. Janousek, R. Mernyi, and L. Stella, Acc. Chem. Res., 18, 148(1985).

16. J. Kopecek, P. Rejmanova, and V. Chytry, Macromol. Chem., 182, 799(1981).

17. The resulting polymer was insoluble in most of the solvents, but soluble in $\mathrm{NaOH}$ aqueous solution and DMSO. The polymer is an amphoteric, and further detailed studies on its structures, properties, and applications are now in progress.

18. P. J. Flory, "Principle of Polymer Chemistry", Cornell University Press, New York, N.Y., (1956).

19. G. F. Fanta, Die Staerke, 29, 413(1977).

20. A. R. Khokhlov, S. G. Starodubtzev, and V. V. Vasilevskaya, Adv. Polym. Sci., 109, 123(1993). 